\title{
КАДРОВЫЙ ПОТЕНЦИАЛ РОССИЙСКИХ ВУЗОВ: СОСТОЯНИЕ И ПЕРСПЕКТИВЫ РАЗВИТИЯ
}

\section{PERSONNEL POTENTIAL OF RUSSIAN UNIVERSITIES: STATE AND DEVELOPMENT PROSPECTS}

\section{N. Garkusha \\ T. Lanets}

Summary: The theory and practice of personnel management asserts that one of the effective tools for the development of modern organizations is personnel strategy and personnel policy, which can be fully attributed to the education system. Like the development strategy of the university, the personnel policy is developed, taking into account the internal resources and traditions of the organization of higher education, as well as the opportunities and threats existing in the external environment. Today universities use personnel management methods aimed at gaining a competitive advantage from their employees. The article provides an analysis of changes in the higher education system of the Russian Federation, as a result of which it is noted that in many universities of the country, even leading ones, there is an acute problem of rejuvenating the composition of the teaching staff and at the same time building up their professional level.

Keywords: personnel policy, personnel potential, personnel management, education system, development strategy, teaching staff of the university.
Гаркуша Наталия Викторовна,

К.nсх.н., дочент, Тихоокеанский государственный университет, Хабаровск

nvi410@mail.ru

Ланец Тамара Николаевна,

К.э.н., дочент, Дальневосточный институт управленияфилиал Российской академии народного хозяйства и государственной службы при Президенте $Р Ф$, Хабаровск tamlan@yandex.ru

Аннотация: Теория и практика управления персоналом утверждает, что одним из эффективных инструментов развития современных организаций является кадровая стратегия и кадровая политика, что в полной мере можно отнести к системе образования. Как и стратегия развития вуза, кадровая политика разрабатывается с учетом внутренних ресурсов и традиций организации высшего образования, а также возможностей и угроз, существующих во внешней среде. Сегодня вузы используют методы управления персоналом, нацеленные на получение от своих работников конкурентного преимущества. В статье дан анализ изменений в системе высшего образования РФ, в результате которого отмечается, что во многих вузах страны, даже ведущих, остро стоит проблема омоложения состава педагогических кадров и одновременно наращивания их профессионального уровня.

Ключевые слова: кадровая политика, кадровый потенциал, управление персоналом, система образования, стратегия развития, профессорско-преподавательский кадровый состав вуза.

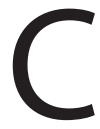
овременные российские вузы постоянно сталкиваются с требованиями изменений, что ведет к обновлению и развитию стратегии, культуры, структуры, технологии, отношений и навыков людей. В процессе изменений требуется комплекс действий по работе с педагогическим персоналом вуза, которые ведут к формированию кадровых политик различной степени новизны. Можно сказать, что кадровая политика запечатлевается в своем продукте - высокопрофессиональном профессорско-преподавательском кадровом составе, а также в результативных кадровых технологиях и методах кадровой работы [1].

В современных исследованиях по данному вопросу определяется несколько вариантов построения кадровых систем, в том числе и применительно к развитию кадрового потенциала профессорско-преподавательского состава образовательной организации. Кадровый потенциал системы образования постоянно меняется, однако тенденции его развития можно проследить на основе динамики важнейших показателей системы образования - уровня финансирования отрасли, числа образовательных организаций, численности профессор- ско-преподавательского состава вузов и других данных.

Изменения в системе образования РФ проявились в разнонаправленных тенденциях: по данным официальной статистики число образовательных организаций высшего образования увеличивалось до 2011 года (на $15 \%$ ), а потом стало стремительно сокращаться, и эта тенденция проявилась как для государственных и муниципальных организаций, так и для частных организаций высшего образования. Общее количество государственных и муниципальных образовательных организаций высшего образования за период с 2010/2011 по 2018/2019 учебный год сократилось примерно на 25\%, а число образовательных организаций частного характера сократилось практически наполовину (на 47 \%). В итоге их число снизилось по сравнению с 2000/2001 годом на 224 единицы, или на 24,2\% (таблица 1).

Вместе с общим сокращением числа образовательных организаций сокращалась численность профессорско-преподавательского состава вузов: она уменьшилась за рассматриваемый период с 307, 4 тысяч человек до 236, 1 тыс. чел. (т.е. на те же 24 \%), а если учитывать, что 
до 2005 г. происходило увеличение штатной численности вузов, то реальное сокращение кадров преподавателей в вузах было еще выше (особенно после 2011 года).

Отметим, что вместе с общим сокращением числа образовательных организаций снизилось число организаций, осуществляющих подготовку научно-педагогических кадров в аспирантуре, а именно на 10,2% в 2018 году по сравнению с 2000 годом (см. данные таблицы 2).

Одной из причин происходившего сокращения было уменьшение числа обучающихся в вузах по всем направлениям подготовки: по сравнению с 2000/2001 г. оно составило примерно 12,3 \%, а по сравнению с наиболее высоким показателем численности обучающихся в 2005/2006 годах это сокращение составило порядка 41 \%. Так что политика общего сокращения числа образовательных организаций и численности педагогически кадров вполне объяснима. Количественные показатели лишь частично отражают ситуацию в отрасли. Качество научно-образовательной деятельности современного образовательного учреждения высшего образования зависит от многих факторов, но в первую очередь, от квалификации профессорско-преподавательского состава. Университеты и образовательные организации высшего образования, ответственно реализующие свою миссию, уделяют должное внимание подготовке научнопедагогических кадров к профессиональной деятельности и стимулируют участие преподавателей в различных программах повышения квалификации, одновременно наращивая трудовой (или кадровый) потенциал.

В литературе разделяют трудовой потенциал работника и трудового коллектива. Трудовой потенциал любого работника определяется как его возможная трудовая дееспособность, его ресурсные возможности в области труда. Трудовой потенциал коллектива предприятия (организации) подразумевает совокупную трудовую дееспособность коллектива, ресурсные возможности в области труда всего списочного состава предприятия, исходя из возраста, имеющихся знаний и профессионально-квалификационных навыков, физических возможностей. Проведем анализ некоторых показателей кадрового потенциала российских вузов за 2017/2018 и 2018/2019 учебные года. Общее сокращение численного состава мы отметили выше. Однако изменилась ли при этом структура кадров, и какова кадровая политика вузов в этом отношении?

По данным таблицы 3, в общем количестве ППС доля докторов наук и кандидатов наук за указанный период несколько увеличилась (д.н. - с 15,4\% до 15, 5\%, к.н. - с

Динамика численности образовательных организаций высшего образования*

Таблица 1. (на начало учебного года) и их кадрового состава

\begin{tabular}{|l|c|c|c|c|c|c|}
\hline показатели & $2000 / 01$ & $2005 / 06$ & $2010 / 11$ & $2016 / 17$ & $2017 / 18$ & $2018 / 19$ \\
\hline всего & 965 & 1068 & 1115 & 818 & 766 & 741 \\
\hline Государственные и муниципальные организации, ед. & 607 & 655 & 653 & 502 & 500 & 496 \\
\hline Частные организации, ед. & 358 & 413 & 462 & 316 & 266 & 245 \\
\hline${\text { численность ППС, тыс. чел. }{ }^{* *}}^{\text {Численность студентов, тыс. чел. }}$ & 307,4 & 387,3 & 356,8 & 261 & 245,1 & 236,1 \\
\hline
\end{tabular}

*C 2016/17 учебного года - включая научные организации, реализующие программы магистратуры.

Источник: составлено авторами по: Образование в цифрах: 2019 : краткий статистический сборник /

Н.В. Бондаренко, Л.М. Гохберг, Н.В. Ковалева и др.; Нац. исслед. ун-т «Высшая школа экономики». М.: НИУ ВШЭ, 2019. - С. 39; ** Россия в цифрах, 2019.- С.142. [5]

Таблица 2.

Организации, осуществляющие подготовку научно-педагогических кадров в аспирантуре (на конец года)

\begin{tabular}{|l|c|c|c|c|c|c|}
\hline годы & 2000 & 2005 & 2010 & 2016 & 2017 & 2018 \\
\hline Всего & 1362 & 1473 & 1568 & 1359 & 1284 & 1223 \\
\hline Научно-исследовательские организации & 797 & 833 & 809 & 733 & 670 & 618 \\
\hline Образовательные организации высшего образования & 565 & 640 & 748 & 611 & 599 & 585 \\
\hline $\begin{array}{l}\text { Образовательные организации дополнительного профес- } \\
\text { сионального образования }\end{array}$ & $\ldots$ & $\ldots$ & 11 & 15 & 15 & 14 \\
\hline
\end{tabular}

Источник: Образование в цифрах: 2019: краткий статистический сборник / Н.В. Бондаренко, Л.М. Гохберг, Н.В. Ковалева и др.; Нац. исслед. ун-т «Высшая школа экономики». - М.: НИУ ВШЭ, 2019. - С.39. [5] 
57,3 до 57,4 \%). Отметим, что изменилась в сторону увеличения не только остепененность кадров вузов, но и другой показатель уровня профессионализма - возросла доля преподавателей, имеющих ученое звание профессора (с 10,1 \% до 10, 4 \%) и доцента (с $36,8 \%$ до 37,2 \%). Можно с уверенностью сказать, что в условиях реализации политики сокращения общего числа образовательных учреждений на государственном уровне вузы одновременно осуществляют более тщательную политику подбора и отбора профессиональных педагогических кадров для образовательных организаций, предъявляют более высокие требования как к подготовке, так и к учебной и внеучебной деятельности кадрового состава.

Анализ кадрового потенциала вузов в Российской Федерации может быть проведен и в возрастном аспекте. В этом ключе можно отметить абсолютное и относительное сокращение численности педагогов в возрасте старше 60 лет (на 0,5 \%) и соответствующее увеличение доли педагогов возрасте от 31 до 59 лет (с 36,8 \% до 37,3 $\%)$, при сохранении на неизменном уровне доли педагогов в возрасте до 30 лет (57,1\%). Такие показатели четко отражают тенденцию к омоложению педагогических коллективов вузов, и одновременное стремление сохранить в составе вузов высокопрофессиональных специалистов, как правило, старших возрастных групп. Для проверки правильности своих выводов мы провели анализ статистических данных из других источников (отчеты ВПО-1 Национальный исследовательский университет «Высшая школа экономики» за 2017-2018 г.). Исход- ные данные представлены в таблице 4, а производные расчеты -в таблице 5.

Данные таблицы 5 показывают, что доля педагогических работников до 30 лет в общем количестве ППС в Национальном исследовательском университете «Высшая школа экономики» составляет 14,6 \%, что значительно ниже среднестатистических официальных данных, а лица старших возрастных групп (свыше 60 лет) также существенно отличаются от средних по отрасли и составляют 18,6\%. Если же принять во внимание уровень профессионализма педагогов, то доля профессоров в старших возрастных группах (свыше 60 лет) составляет $46,9 \%$, а доля доцентов - $14 \%$ от их общего количества в данной профессиональной группе. Исходя из данных таблицы можно заметить, что получение звания доцента происходит очень активно в возрасте от 30 до 40 лет, а звание профессора педагоги получают в основной массе ближе к 50 годам и старше.

С целью проверки данных выводов мы изучили данные мониторинга системы высшего образования по всем вузам Российской Федерации за 2013-2019 гг. Выборочные данные за 2019 год представлены в таблице 6. В качестве объекта анализа выбраны выборочно вузы Центрального федерального округа (г. Москва), а также вузы других федеральных округов - Уральского, Южного, Сибирского, Дальневосточного с разной численностью профессорско-преподавательского состава.

Данные мониторинга отражают несколько иную за-

Таблица 3.

Профессорско-преподавательский состав организаций, осуществляющих образовательную деятельность по программам бакалавриата, специалитета, магистратуры

\begin{tabular}{|l|c|c|c|c|}
\hline \multicolumn{1}{|c|}{ Показатели } & $2017 / 18$ & $2018 / 19$ & $2017 / 18$ & $2018 / 19$ \\
\cline { 2 - 5 } & Тыс.чел. & Тыс.чел. & В \% к итогу & В \% к итогу \\
\hline ППС (без внешних совместителей), тыс. чел. & 245,1 & 236,1 & 100 & 100 \\
\hline Из них: & & & \\
\hline имеют ученую степень & & & \\
\hline Доктора наук & 37,8 & 36,6 & 15,4 & 15,5 \\
\hline Кандидата наук & 140,5 & 135,6 & 57,3 & 57,4 \\
\hline РНD & 0,6 & 0,7 & 0,25 & 0,3 \\
\hline имеют ученое звание & & & & 10,1 \\
\hline профессора & 25 & 24,6 & 10,4 \\
\hline доцента & 90,3 & 88 & 36,8 & 37,2 \\
\hline лица в возрасте до 30 лет* & 139,9 & 134,8 & 57,1 & 57,1 \\
\hline лица в возрасте 60 лет и старше* & 14,8 & 13,1 & 6,0 & 5,5 \\
\hline
\end{tabular}

* Число полных лет на 1 января.

Источник: Образование в цифрах: 2019: краткий статистический сборник / Н.В. Бондаренко,

Л.М. Гохберг, Н.В. Ковалева и др.; Нац. исслед. ун-т «Высшая школа экономики». - М.: НИУ ВШЭ, 2019. - С. 69. [5] 
Распределение научно-педагогического персонала по возрасту в Национальном исследовательском университете «Высшая школа экономики»

\begin{tabular}{|c|c|c|c|c|c|c|c|c|c|c|c|}
\hline \multirow{3}{*}{ показатели } & \multirow{3}{*}{$\begin{array}{l}\text { Всего, } \\
\text { чел. }\end{array}$} & \multicolumn{10}{|c|}{ Число полных лет по состоянию на 1 января 2018 года } \\
\hline & & менее 25 & $25-29$ & $30-34$ & $35-39$ & $40-44$ & $45-49$ & $50-54$ & $55-59$ & $60-64$ & 65 и более \\
\hline & & всего & всего & всего & всего & всего & всего & всего & всего & всего & всего \\
\hline $\begin{array}{l}\text { Профессорско-преподавательский } \\
\text { состав - всего }\end{array}$ & 2086 & 52 & 252 & 279 & 302 & 220 & 166 & 210 & 218 & 169 & 218 \\
\hline $\begin{array}{l}\text { в том числе: } \\
\text { деканы факультетов }\end{array}$ & 12 & - & 1 & - & - & 2 & 1 & 3 & 2 & 2 & 1 \\
\hline профессора & 451 & - & - & 6 & 14 & 34 & 40 & 65 & 76 & 76 & 140 \\
\hline доценты & 909 & - & 47 & 154 & 177 & 126 & 90 & 83 & 104 & 64 & 64 \\
\hline старшие преподаватели & 463 & 1 & 87 & 85 & 92 & 48 & 30 & 52 & 32 & 25 & 11 \\
\hline преподаватели, ассистенты & 251 & 51 & 117 & 34 & 19 & 10 & 5 & 7 & 4 & 2 & 2 \\
\hline
\end{tabular}

Национальный исследовательский университет «Высшая школа экономики», 2018 г.

Таблица 5.

Структура кадрового состава Высшей школы экономики по возрасту в 2018 г., в \% к итогу

\begin{tabular}{|c|c|c|c|c|c|}
\hline \multirow{2}{*}{$\begin{array}{c}\text { Структура персонала по } \\
\text { возрасту, в т.ч. лет }\end{array}$} & \multirow[b]{2}{*}{ ППС всего } & \multicolumn{4}{|c|}{ В том числе по группам персонала } \\
\hline & & Профессора & доценты & $\begin{array}{c}\text { старшие } \\
\text { преподаватели }\end{array}$ & ассистенты \\
\hline менее 25т & 2,5 & 0,0 & 0,0 & 0,2 & 19,4 \\
\hline $25-29$ & 12,1 & 0,0 & 5,2 & 18,8 & 44,9 \\
\hline $30-34$ & 13,4 & 1,3 & 16,9 & 18,4 & 12,9 \\
\hline $35-39$ & 14,5 & 3,1 & 19,5 & 19,9 & 7,2 \\
\hline $40-44$ & 10,5 & 7,5 & 13,9 & 10,4 & 4,6 \\
\hline $45-49$ & 8,0 & 8,9 & 9,9 & 6,5 & 2,3 \\
\hline $50-54$ & 10,1 & 14,4 & 9,1 & 11,2 & 3,8 \\
\hline $55-59$ & 10,5 & 16,9 & 11,4 & 6,9 & 2,3 \\
\hline $60-64$ & 8,1 & 16,9 & 7,0 & 5,4 & 1,5 \\
\hline свыше 65 & 10,5 & 31,0 & 7,0 & 2,4 & 1,1 \\
\hline Итого & 100 & 100 & 100 & 100 & 100 \\
\hline
\end{tabular}

Национальный исследовательский университет «Высшая школа экономики», 2018 г.

кономерность, нежели та, что нашла отражение в официальной статистике. Доля молодых педагогов в общей численности персонала (до 40 лет включительно) во всех представленных вузах колеблется от $22 \%$ до $40 \%$, а доля лиц старших возрастных групп (старше 65 лет) тоже достаточно высока и колеблется в диапазоне от 15 до 30 \% в среднем. Это означает, что во многих вузах страны, даже ведущих, остро стоит проблема омоложения состава педагогических кадров и одновременно наращивания их профессионального уровня.

Развитие кадрового потенциала вузов сегодня является неотъемлемой частью целостной кадровой полити- ки образовательной организации высшего образования [3]. В ходе анализа кадрового потенциала российских вузов по представлению сведений о повышении квалификации педагогического состава и возрастному составу, нами были выявлены основные проблемы:

- старение кадрового состава научно-педагогических работников;

- недостаточная привлекательность преподавательской работы для выпускников вузов (это видно из данных статистики по количеству ассистентов и преподавателей);

- низкая активность аспирантуры и докторантуры (последние 3 года идет спад активности молодых 
Таблица 6.

Структура кадрового потенциала вузов Российской Федерации по возрасту в 2019 году

\begin{tabular}{|c|c|c|c|c|c|c|c|}
\hline Показатели кадрового потенциала & $\begin{array}{l}\text { Ед. } \\
\text { изм }\end{array}$ & $\begin{array}{c}\text { ФГБОУ во } \\
\text { МГУ имени } \\
\text { Ломоносова* }\end{array}$ & $\begin{array}{l}\text { ФГАОУ ВО НИУ } \\
\text { МИЭТ }^{* *}\end{array}$ & $\begin{array}{l}\text { ФГАОУ ВО } \\
\text { МФТИ (НИУ) } \\
* * *\end{array}$ & $\begin{array}{c}\text { ФГАОУ ВО } \\
\text { НИУ ВШЭ **** }\end{array}$ & $\begin{array}{c}\text { Сеченовский } \\
\text { Университет } \\
\text { ***** }\end{array}$ & $\begin{array}{l}\text { ФГБоУ во РХТу } \\
\text { им. Менделеева } \\
* * * * * *\end{array}$ \\
\hline $\begin{array}{l}\text { Общая численность ППС (без внешних } \\
\text { совместителей и работающих } \\
\text { по договорам ГПХ) }\end{array}$ & чел & 5046 & 362 & 408 & 1451 & 1731 & 511 \\
\hline $\begin{array}{l}\text { Доля ППС возрастной категории } \\
\text { моложе } 40 \text { лет }\end{array}$ & $\%$ & 22,49 & 22,65 & 30,15 & 39,63 & 29,4 & 26,61 \\
\hline $\begin{array}{l}\text { Доля ППС возрастной категории } \\
\text { моложе } 65 \text { лет }\end{array}$ & $\%$ & 70,67 & 66,02 & 70,1 & 87,18 & 84,06 & 69,67 \\
\hline $\begin{array}{l}\text { Доля ППС возрастной категории } \\
\text { старше } 65 \text { лет }\end{array}$ & $\%$ & 29,33 & 33,98 & 29,9 & 12,82 & 15,94 & 30,33 \\
\hline Доля ППС, имеющих ученые степени & $\%$ & 80,08 & 69,89 & 71,08 & 67,95 & 73,31 & 75,15 \\
\hline Показатели кадрового потенциала & $\begin{array}{l}\text { Ед. } \\
\text { изм }\end{array}$ & РАНХиГС & Чеченский ГПУ & ФГАОУ ВО ЮФУ & ФГАОУ ВО УФУ & $\begin{array}{l}\text { ФГБОУ ВО } \\
\text { ПГНИУ }\end{array}$ & ДВИУ РАНХИГС \\
\hline $\begin{array}{l}\text { Общая численность ППС (без внешних } \\
\text { совместителей и работающих по до- } \\
\text { говорам ГПХ) }\end{array}$ & чел & 1032 & 238 & 1827 & 2152 & 780 & 74 \\
\hline $\begin{array}{l}\text { Доля ППС возрастной категории } \\
\text { моложе } 40 \text { лет }\end{array}$ & $\%$ & 25,19 & 33,19 & 31,31 & 29,41 & 37,69 & 24.32 \\
\hline $\begin{array}{l}\text { Доля ППС возрастной категории } \\
\text { моложе } 65 \text { лет }\end{array}$ & $\%$ & 80,62 & 94,96 & 84,56 & 77,14 & 82,56 & 85.14 \\
\hline $\begin{array}{l}\text { Доля ППС возрастной категории } \\
\text { старше } 65 \text { лет }\end{array}$ & $\%$ & 19,38 & 5,04 & 15,44 & 22,86 & 17,44 & 14,86 \\
\hline Доля ППС, имеющих ученые степени & $\%$ & 65,89 & 60,5 & 75,53 & 70,03 & 70,26 & 74,32 \\
\hline
\end{tabular}

Источник: indicators.miccedu.ru/monitoring/?m=vpo

Примечание: (сокращение наименований вузов)

* ФГБОУ ВО «МГУ имени М.В. Ломоносова»

**ФГАОУ ВО «Национальный исследовательский университет «Московский институт электронной техники»(НИУ МИЭТ)

***ФГАОУ ВО «Московский физико-технический институт (национальный исследовательский университет) «МТИ (НИУ)»

****ФГАОУ ВО «Национальный исследовательский университет «Высшая школа экономики» (НИУ ВШЭ)

*****ФГАОУ ВО Первый Московский государственный медицинский университет имени И.М. Сеченова

Министерства здравоохранения Российской Федерации (Сеченовский Университет)»

****** ФГБОУ ВО Российский химико-технологический университет имени Д.И. Менделеева» («РХТУ

имени Д.И. Менделеева»)

ФГБОУ ВО «Российская академия народного хозяйства и государственной службы при Президенте Российской Федерации» (РАНХи ГС)

ФГАОУ ВО «Южный федеральный университет» (ЮФУ)

ФГАОУ ВО «Уральский федеральный университет имени первого Президента России Б.Н. Ельцина» (УФУ) ФГБОУ ВО «Пермский государственный национальный исследовательский университет» (ПГНИУ)

специалистов, получивших ученые степени, так в 2014 г. средний показатель по российским вузам 57\%, а в 2017 год 34\% научно-педагогических работников получили ученую степень кандидата или доктора наук);

- недостаточное развитие системы профессионального повышения квалификации ведущих университетах, стажировок за рубежом (либо отсутству- 
ют полностью, либо не более 7\% от общего числа научно-педагогических работников вуза).

Выявленные проблемы развития кадрового потенциала в высшем учебном заведении не позволяют поднять статус вуза и высшего образования на уровень, способный отвечать запросам рынка и государственной политики по формированию новой экономики. Указанные выше причины не позволяют обеспечить в полной мере становление конкурентоспособных молодых профессиональных кадров; повышение профессионального уровня преподавательского состава вуза; эффективное взаимодействие вуза с рынком труда; повышение инновационного потенциала вуза.

Вопросы, касающиеся повышения потенциала профессорско-преподавательского состава российских ВУЗов, систематического анализа эффективности повышения педагогической квалификации ППС и др., должны лечь в основу деятельности вузов [4].

В этой связи, мы видим необходимость систематического проведения количественного и качественного анализа преподавательского состава вуза, с учетом прогнозной потребности, использование механизмов автоматизации сбора информации по показателям научной, инновационной и педагогической деятельности научнопедагогического состава вуза. Такой подход требует совершенствования кадровой политики образовательной организации высшего образования, которая должна строиться в том числе и с учетом следующих принципов:

- преемственность в передаче научно-методического опыта и профессиональной компетентности от педагогов-наставников молодым педагогам;

- разработка единой модели компетенций профессорско-педагогических кадров;

- введение квалификации преподаватель-исследователь;

- систематический комплексный анализ и прогнозирование потребности в педагогических кадрах;

- прозрачность и объективность методов контроля деятельности профессорско-педагогического состава, четко встроенных в процесс управления вузом;

- создание условий труда для эффективного выполнения преподавателями своих профессиональных задач;

- правовая и социальная защита, соблюдение академических свобод преподавателей, обеспечение законности и социальной справедливости в решении кадровых вопросов.

Для нас представляют интерес проведение маркетинговых исследований в сфере кадрового потенциала вуза и его самосовершенствование. Огромное значение для достижения синергетического эффекта имеет интеграция образовательных и научных процессов, которая позволит повысить профессиональный уровень преподавательского состава вуза, поможет вовлечь молодых педагогов в научную деятельность, даст возможность прохождения квалифицированного обучения в своей сфере деятельности, повышение эффективности функционирования структурных подразделений по направлениям деятельности высшего учебного заведения.

Кадровая политика вузов должна быть направлена на восполнение собственного кадрового потенциала за счет своих выпускников. Так в образовательных организациях высшего образования необходимо создавать и поддерживать целевые, корпоративные программы отбора и подготовки к педагогической деятельности молодых педагогов, где основным элементом должна стать комбинированная учебно-исследовательская деятельность. В программу необходимо включать базовые знания по педагогике и психологии, технологиям образовательной деятельности и способам их оценки, этическим и правовым аспектам образования, использованию современных цифровых образовательных технологий; владению навыками публичных выступлений, техникой речи, тактикой и логикой ведения дискуссии[2]. На начальном этапе профессиональной деятельности необходимо знакомить молодого педагога с целями и задачами учебно-воспитательной работы со студентами, современными методами её организации, учить устанавливать контакт с аудиторией и управлять ею. Формирование профессиональных педагогических компетенций у молодых педагогов носит, как правило, индивидуальный характер и проходит в том числе и в процессе его самостоятельной работы.

Также, с целью восполнения собственного кадрового потенциала за счет своих выпускников можно предложить на кафедрах вузов ввести в магистерские программы, направленные на подготовку выпускника к преподавательской деятельности. В учебные планы этих программ дополнительно внести дисциплины по психологии и педагогике высшей школы, предусмотреть большой объем педагогической практики. По нашей оценке, это будет способствовать формированию у выпускников магистерских программ профессиональных педагогических компетенций.

Подготовка будущих преподавателей для вуза представляет собой «поэтапный профессиональный рост обучающихся от магистра до профессора». Технология подготовки молодого преподавателя должна включать следующие стадии:

- отбор студентов (претендентов) на старших курcax; 
- оценка уровня начальной подготовки;

- зачисление на преподавательскую должность по приказу ректора на один год (испытательный срок);

- работа под руководством профессора или ведущего доцента в течение года на кафедре по инди- видуальному плану;

— анализ и оценка дальнейших перспектив работы.

По нашему мнению, данное направление кадровой работы должно стать одним из эффективных способов наращивания кадрового потенциала вуза.

\section{ЛИТЕРАТУРА}

1. Баталова 0.С. Конкурентоспособность вуза на рынке образовательных услуг // Молодой ученый. - 2010. - №10. - C. 53-58. - URL https://moluch.ru/ archive/21/2111/ (дата обращения: 02.02.2020))

2. Владимиров А.И. 0 профессорско-преподавательском составе технических вузов - центральном звене в подготовке инженерных кадров. М.: 000 «Издательский дом Недра», 2016. - 111 с.

3. Гаркуша, Н.В. Ланец Т.Н. Вуз как самообучающаяся организация / Н.В. Гаркуша, Т.Н. Ланец // Материалы Международной научно-методической конференции «Проблемы высшего образования»/ под ред. Т.В. Гомза - Хабаровск: Изд-во Тихоокеан. гос.ун-та, 2018. -с.11-13

4. Гаркуша, Н.В. Современные технологии обучения в системе подготовки и повышения квалификации педагогических кадров высшей школы / Н.В. Гаркуша //Сборник научных трудов «Психология профессиональной деятельности: проблемы, содержание, ресурсы» / под. ред. Е.Н. Ткач. Хабаровск: Изд-во Тихоокеан. гос.ун-та, 2019. -с.93-101

5. Образование в цифрах: 2019: краткий статистический сборник / Н.В. Бондаренко, Л.М. Гохберг, Н.В. Ковалева и др.; Нац. исслед. ун-т «Высшая школа экономики». - М.: НИУ ВШЭ, 2019.

6. indicators.miccedu.ru/monitoring/?m=vpo

(c) Гаркуша Наталия Викторовна (nvi410@mail.ru), Ланец Тамара Николаевна (tamlan@yandex.ru).

Журнал «Современная наука: актуальные проблемы теории и практики»

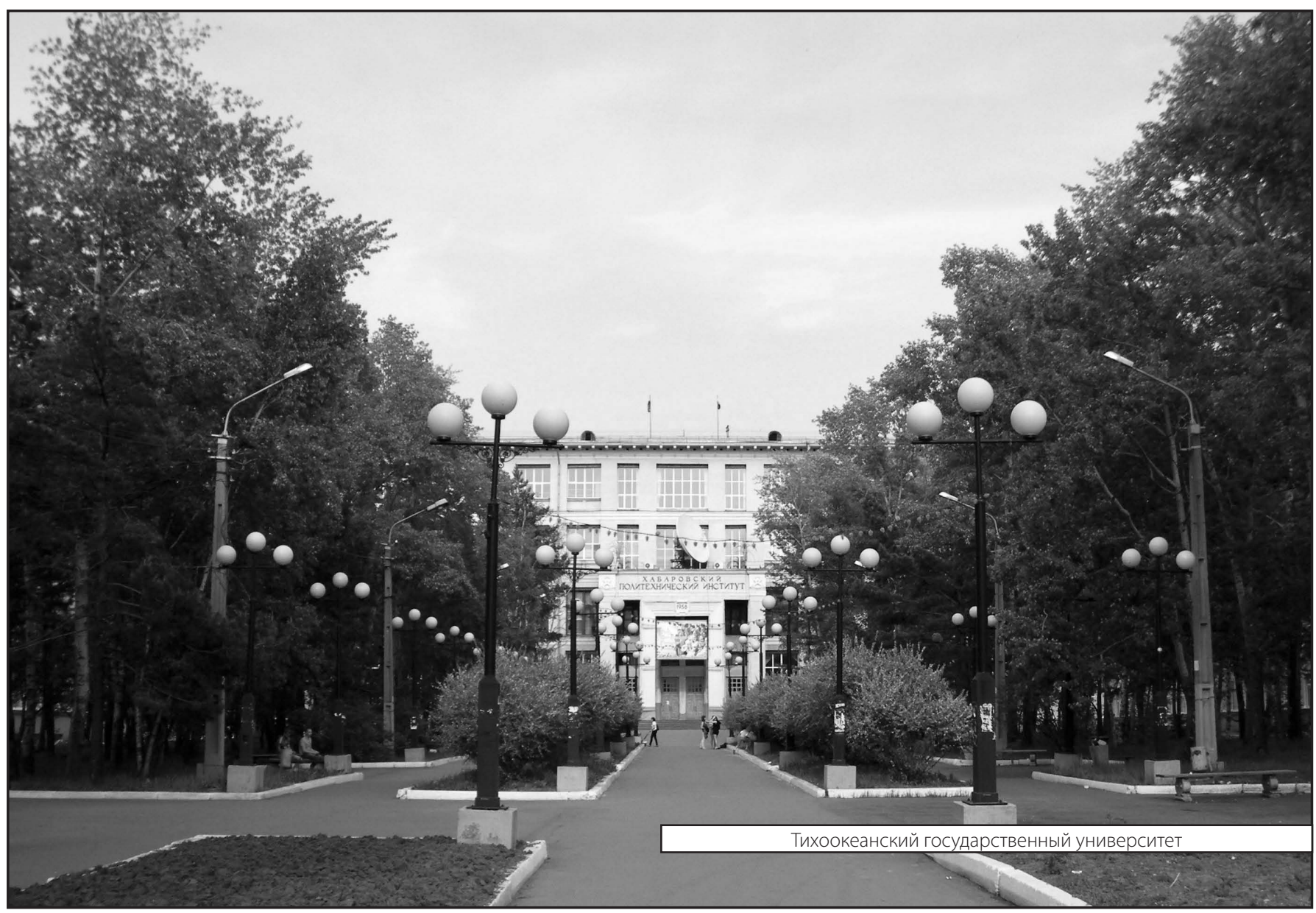

